M.M. van Riemsdijk $\cdot$ J.M. Ditters

M.C.J.M. Sturkenboom · J.H.M. Tulen

R.J. Ligthelm · D. Overbosch · B.H.Ch. Stricker

\title{
Neuropsychiatric events during prophylactic use of mefloquine before travelling
}

Received: 9 January 2002 / Accepted in revised form: 27 May 2002 / Published online: 27 July 2002

(C) Springer-Verlag 2002

\begin{abstract}
Introduction: It has been suggested that neuropsychiatric events during use of mefloquine are more common in females than in males and are partly explained by the psychological stress of travelling. Therefore, we investigated neuropsychiatric events in females and males on mefloquine in the 3-week prophylactic period that precedes travelling. Furthermore, we investigated whether first-time users had a higher risk of neuropsychiatric adverse events than subjects with a history of mefloquine use.

Methods: We enrolled all patients who visited a Travel Clinic for mefloquine prophylaxis during the period 1 May 1999 to 7 March 2000. Each patient was followed from baseline (prior to starting mefloquine) up to 3 weeks after the start of mefloquine but before travelling. We asked patients to register any adverse event in a diary and measured the intra-individual change in scores on the Dutch Shortened Profile Of Mood States (POMS) at baseline and at the end of follow-up.

Results: The final cohort consisted of 179 subjects with a mean age of 3 years. Females reported adverse events more frequently than males $(P=0.005)$. Overall, we observed a small but significant increase in the score on the domain fatigue $[0.74$ points, $95 \%$ confidence interval (CI) $0.18,1.30]$. The effect was exclusively present in
\end{abstract}

M.M. van Riemsdijk · M.C.J.M. Sturkenboom

B.H.Ch. Stricker $(\square)$

Department of Epidemiology and Biostatistics,

Erasmus MC, Grasmus University Rotterdam,

PO Box 1738, 3000 DR Rotterdam, the Netherlands

E-mail: stricker@epib.fgg.eur.nl

Fax: + 31-10-4089382

J.M. Ditters

Department of Pharmacotherapy and Pharmacoepidemiology,

Utrecht University, Utrecht, the Netherlands

J.H.M. Tulen

Department of Psychiatry, Erasmus MC,

Grasmus University Rotterdam, Rotterdam, the Netherlands

R.J. Ligthelm · D. Overbosch

Travel Clinic, Havenziekenhuis and Institute for Tropical Diseases, Rotterdam, the Netherlands females and not in males. First-time users of mefloquine increased 2.81 points $(95 \%$ CI $0.70,4.92)$ on the total score of the POMS, and among those, women showed the largest increase of 4.58 points $(95 \%$ CI $0.74,8.43)$. Conclusion: The use of mefloquine was associated with neuropsychiatric adverse effects. Females encountered neuropsychiatric effects more frequently than males, which could be confirmed by validated psychological tests. Neuropsychiatric effects were more common in first-time users than in individuals who had used mefloquine before.

Keywords Neuropsychiatric events · Prophylaxis · Mefloquine

\section{Introduction}

In the Netherlands, mefloquine is currently the first choice for malaria prophylaxis in travellers staying more than 7 nights in areas with chloroquine-resistant falciparum malaria [1]. Mefloquine is a quinoline derivative that is used in a dose of $250 \mathrm{mg}$ weekly. In order to obtain adequate prophylactic blood levels and to detect adverse effects at an early stage, mefloquine is usually started 3 weeks before travelling. During the last years, case reports on neuropsychiatric adverse events and subsequent media attention have influenced the public opinion on the use of mefloquine $[2,3,4,5]$. Two types of neuropsychiatric adverse events have been attributed to the use of mefloquine: (1) a sensation of dizziness, dysphoria, light-headedness and difficulty in concentrating which occurs within $6 \mathrm{~h}$ after intake and usually resolves during the following days; (2) acute psychosis with agitation or depression, occurring in the second week after starting prophylaxis [6]. In a previous study, we found that women in particular developed insomnia on mefloquine [7]. Other studies also found more neuropsychiatric effects in women than in men $[8,9]$. Several studies, however, did not take into account the stress of travelling itself. Some authors have suggested that physiological and 
psychological stress of intercontinental travel may confound the association between mefloquine and neuropsychiatric adverse events $[8,10,11]$. Therefore, we further explored the difference between neuropsychiatric adverse effects in males and females on mefloquine during the 3-week prophylactic period that precedes travelling. Furthermore, we investigated whether first-time users had a higher risk of neuropsychiatric adverse events than subjects with a history of mefloquine use.

\section{Methods}

We conducted a prospective cohort study in the Travel Clinic of the Havenziekenhuis and Institute for Tropical Diseases Rotterdam, the Netherlands. The study was approved by the local medical ethics committee.

\section{Cohort definition}

Our potential study population consisted of all persons who visited the travel clinic for malaria prophylaxis during the study period that started 1 May 1999 and ended 7 March 2000. Subjects were recruited at the first visit (baseline), during which they were asked for written informed consent. Follow-up ended at a scheduled visit 2 weeks or 3 weeks after starting prophylaxis but always prior to departure to the tropics. We included all subjects who received a prescription for mefloquine and excluded all persons who had either one or more contraindications for mefloquine (history of epilepsy, psychosis or depression, known allergy or sensitivity to mefloquine, concurrent use of cardiovascular medication). Subsequently, we excluded subjects who had used mefloquine in the preceding 2 months and those who had other risk factors for concentration impairment (e.g. use of opioids, hypnotics or tranquillisers during the 2 weeks prior to testing, use of alcohol $4 \mathrm{~h}$ prior to testing).

\section{Outcomes}

We studied two different outcomes. The first outcome measure was the intra-individual change in score on the Dutch Shortened Profile Of Mood States (POMS). The POMS is a validated questionnaire for the measurement of subjective mood. The POMS contains 32 questions and is designed to measure feelings in five domains: tension, depression, anger, fatigue and vigour. The answers are graded on a five-point scale ranging from "not at all" (scale 0) to "extremely" (scale 4) [12]. The total mood disturbance (TMD) is a composite overall score, which can be calculated by summing the raw scores across the four categories (tension, anger, fatigue and depression) and subtracting vigour. The calculated total score ranges from -20 to 108 , and an increase in TMD means an increase of mood disturbance. For every subject, the reference score was assessed before start of therapy (baseline date) and the index score after the second or third tablet of mefloquine (index date), shortly before travelling.

The second outcome was the occurrence of neuropsychiatric adverse events. All subjects were asked to register all adverse events that were encountered during the first 3 weeks of use of mefloquine in a diary.

\section{Exposure to mefloquine}

Previous exposure to mefloquine was assessed using a questionnaire at baseline. Use of mefloquine during the study period was assessed by means of a diary sheet on which subjects were asked to fill out dose and dosing times from the start until the end of follow-up. Compliance with use of mefloquine was assessed on the basis of diary recordings.

\section{Covariates}

Data were gathered at baseline on demographics, weight, height, education, travel destination and chronic co-morbidity. Furthermore, data on risk factors, which may vary over time and which are potentially related to the outcomes on the POMS scales, were collected at the start and at the end of follow-up. These included the use of alcohol, coffee, co-medication and illicit drugs.

\section{Analysis}

We calculated that to demonstrate a standardised difference in TMD of 0.5 with a power of 0.8 at a two-sided significance level of 0.05 and assuming a participation rate of $80 \%$, would require approximately 150 individuals. The primary comparison comprised the intra-individual change (delta) in the scores on the POMS domains between baseline and at the end of follow-up. Univariate analyses of continuous variables were conducted by means of paired $t$-tests. In order to study the association between timeindependent covariates such as co-morbidity, age and gender and the change in scores we used linear-regression models. In a second step, we identified through stratification whether the intra-individual effects were associated with previous use of mefloquine and with the self-reported neuropsychiatric adverse events. In order to study the association between time-dependent covariates such as use of coffee and medication and the change in scores, we used the general linear model for repeated measurements. All tests were twosided with rejection of the null hypothesis at a $P$ value less than 0.05 . The risk of neuropsychiatric adverse events as reported by the subjects within the first weeks of use were calculated for persons who completed follow-up (per protocol analysis) and for all persons who were initially recruited. Furthermore, to check internal consistency we compared the change in scores on the POMS in subjects with and without self-reported adverse events.

\section{Results}

We enrolled a total of 200 subjects in the cohort, of whom $179(89.5 \%)$ completed follow-up. Reasons for loss to follow-up were: withdrawal of informed consent $(n=12)$, cessation of mefloquine because of neuropsychiatric adverse effects $(n=5)$, cancelling of the trip $(n=3)$ and moving to another part of the Netherlands $(n=1)$. Of the 21 subjects dropping out, $9(42.9 \%)$ were female. Comparison of the scores on the POMS at baseline showed that dropouts had significantly higher scores on the domains tension and depression than participants.

Hence, the final cohort for whom we obtained scores on the POMS on both occasions consisted of 179 subjects with a mean age of 39 years. General characteristics of the study population are presented in Table 1. Only $9 \%$ of subjects were experiencing medical complaints at the time of enrolment but these were non-serious. No differences were observed between males and females regarding age, highest education, marital status, number of smokers and presence of medical complaints at baseline. The travel destination was predominantly Africa $(67.4 \%)$ and the reason for travelling tourism (Table 1). The majority of the study population planned their travel together with others $(88.8 \%)$. We observed no differences between males and females regarding the travel characteristics. In our cohort, 70 subjects $(39.3 \%)$ had used mefloquine before, and 21 subjects $(30.4 \%)$ 
Table 1. General characteristics of the study population

\begin{tabular}{|c|c|c|c|}
\hline & Total $(n=179)$ & Males $(n=95)$ & Females $(n=84)$ \\
\hline $\begin{array}{l}\text { Average age in years (range) } \\
\text { BMI }\left(\mathrm{kg} / \mathrm{m}^{2}, \text { range }\right)\end{array}$ & $\begin{array}{l}39(11-76) \\
24.1(15.8-35.8)\end{array}$ & $\begin{array}{l}40(11-68) \\
24.9(15.8-35.8)\end{array}$ & $\begin{array}{l}37(15-76) \\
23.2(17.0-33.3)\end{array}$ \\
\hline $\begin{array}{l}\text { Highest education }^{\mathrm{a}} \\
\text { Primary/vocational education } \\
\text { Secondary/vocational education } \\
\text { College/university }\end{array}$ & $\begin{array}{l}16(9.1 \%) \\
79(44.9 \%) \\
81(46.0 \%)\end{array}$ & $\begin{array}{l}11(11.8 \%) \\
43(46.2 \%) \\
39(41.9 \%)\end{array}$ & $\begin{array}{c}5(6.0 \%) \\
36(43.4 \%) \\
42(50.6 \%)\end{array}$ \\
\hline $\begin{array}{l}\text { Marital status }^{\mathrm{a}} \\
\text { Unmarried } \\
\text { Married/living together } \\
\text { Divorced }\end{array}$ & $\begin{aligned} & 70(40.2 \%) \\
& 100(57.5 \%) \\
& 4(2.3 \%)\end{aligned}$ & $\begin{array}{c}39(42.4 \%) \\
50(54.3 \%) \\
3(3.3 \%)\end{array}$ & $\begin{array}{c}31(37.8 \%) \\
50(61.0 \%) \\
1(1.2 \%)\end{array}$ \\
\hline $\begin{array}{l}\text { Smoking }^{\mathrm{a}} \\
\text { Yes } \\
\text { No }\end{array}$ & $\begin{array}{r}44(24.7 \%) \\
134(75.3 \%)\end{array}$ & $\begin{array}{l}24(25.3 \%) \\
71(74.7 \%)\end{array}$ & $\begin{array}{l}20(24.1 \%) \\
63(75.9 \%)\end{array}$ \\
\hline $\begin{array}{l}\text { Medical complaints } \\
\text { Yes } \\
\text { No }\end{array}$ & $\begin{array}{c}16(9.0 \%) \\
161(91.0 \%)\end{array}$ & $\begin{array}{c}7(7.4 \%) \\
88(92.6 \%)\end{array}$ & $\begin{array}{r}9(11.0 \%) \\
73(89.0 \%)\end{array}$ \\
\hline $\begin{array}{l}\text { Destination of travel }^{\mathrm{a}} \\
\text { Africa } \\
\text { Asia } \\
\text { South America } \\
\text { Combined }\end{array}$ & $\begin{aligned} 120 & (67.4 \%) \\
48 & (27.0 \%) \\
8 & (4.5 \%) \\
2 & (1.1 \%)\end{aligned}$ & $\begin{aligned} 65 & (68.4 \%) \\
25 & 26.3 \%) \\
4 & (4.2 \%) \\
1 & (1.1 \%)\end{aligned}$ & $\begin{array}{c}55(66.3 \%) \\
23(27.7 \%) \\
4(4.8 \%) \\
1(1.2 \%)\end{array}$ \\
\hline $\begin{array}{l}\text { Reason for travelling } \\
\text { Business } \\
\text { Tourist } \\
\text { Both }\end{array}$ & $\begin{array}{c}10(5.7 \%) \\
149(85.1 \%) \\
16(9.1 \%)\end{array}$ & $\begin{array}{c}5(5.4 \%) \\
77(83.7 \%) \\
10(10.9 \%)\end{array}$ & $\begin{array}{c}5(6.0 \%) \\
72(86.7 \%) \\
6(7.2 \%)\end{array}$ \\
\hline $\begin{array}{l}\text { Travelling alone }{ }^{\mathrm{a}} \\
\text { Yes } \\
\text { No }\end{array}$ & $\begin{array}{r}20(11.2 \%) \\
158(88.8 \%)\end{array}$ & $\begin{array}{l}10(10.5 \%) \\
85(89.5 \%)\end{array}$ & $\begin{array}{l}10(12.0 \%) \\
73(88.0 \%)\end{array}$ \\
\hline
\end{tabular}

${ }^{a}$ Numbers do not add up to total since some subjects did not answer all questions $B M I$ body mass index had encountered non-serious adverse events during previous use of mefloquine. Upon prompting by questionnaire, 58 subjects ( 21 males and 37 females) reported neuropsychiatric adverse events attributed to the use of mefloquine (cumulative incidence for per protocol analysis: $32.4 \%$; idem for intention-to-treat analysis: $31.5 \%$ ). Females reported adverse events more frequently than males $(P=0.002)$. The most frequently reported adverse events comprised insomnia $(n=23)$, headache $(n=15)$, fatigue $(n=14)$, dizziness $(n=13)$, abnormal dreams/nightmares $(n=12)$ and anxiety/depression/emotional lability $(n=9)$. The risk of at least one neuropsychiatric adverse event was $44.6 \%$ for females $[95 \%$ confidence interval $(\mathrm{CI}) 34.5 \%, 54.7 \%]$ and $22.1 \%$ for males $(95 \%$ CI $13.8 \%, 30.4 \%)$. The risk of neuropsychiatric adverse events during the first 3 weeks of first-time use of mefloquine was $38.0 \% \quad(95 \%$ CI $28.8 \%, 47.1 \%$ ) and in those with a history of use $24.3 \%$ $(95 \%$ CI $14.2 \%, 34.3 \%)$. With respect to the POMS, we observed small increases during follow-up on all domains but the change was only significant on the domain fatigue and TMD for females (Table 2). No changes were observed in males. Adjustment for time-dependent covariates did not affect the results. Stratification for history of use of mefloquine showed that the TMD and the scores on the domains anger and vigour differed between first-time users and those who had used me-
Table 2. Changes in scores on the profile of mood states (POMS)

\begin{tabular}{|c|c|c|c|c|c|}
\hline & \multicolumn{2}{|l|}{ Score } & \multirow{2}{*}{$\begin{array}{l}\text { Mean } \\
\text { difference } \\
\text { t1-t0 }\end{array}$} & \multirow[t]{2}{*}{$95 \% \mathrm{CI}$} & \multirow[t]{2}{*}{$P$ value } \\
\hline & to & $\mathrm{t} 1$ & & & \\
\hline \multicolumn{6}{|c|}{ Total population } \\
\hline Tension & 1.86 & 1.96 & 0.10 & $-0.31,0.51$ & 0.629 \\
\hline Depression & 0.53 & 0.86 & 0.33 & $-0.02,0.67$ & 0.061 \\
\hline Anger & 1.54 & 1.64 & 0.10 & $-0.48,0.68$ & 0.734 \\
\hline Fatigue & 2.50 & 3.24 & 0.74 & $0.18,1.30$ & $0.010^{*}$ \\
\hline Vigour & 11.33 & 11.31 & -0.02 & $-0.60,0.56$ & 0.940 \\
\hline TMD & -4.90 & -3.60 & 1.30 & $-0.30,2.89$ & 0.111 \\
\hline \multicolumn{6}{|l|}{ Males } \\
\hline Tension & 1.72 & 1.80 & 0.08 & $-0.44,0.61$ & 0.751 \\
\hline Depression & 0.33 & 0.44 & 0.11 & $-0.11,0.34$ & 0.303 \\
\hline Anger & 1.79 & 1.39 & -0.40 & $-1.13,0.33$ & 0.282 \\
\hline Fatigue & 2.08 & 2.48 & 0.40 & $-0.28,1.08$ & 0.246 \\
\hline Vigour & 11.85 & 12.26 & 0.41 & $-0.33,1.16$ & 0.277 \\
\hline TMD & -5.94 & -6.15 & -0.21 & $-1.85,1.43$ & 0.800 \\
\hline \multicolumn{6}{|l|}{ Females } \\
\hline Tension & 2.02 & 2.14 & 0.12 & $-0.53,0.77$ & 0.717 \\
\hline Depression & 0.76 & 1.33 & 0.57 & $-0.12,1.27$ & 0.106 \\
\hline Anger & 1.26 & 1.93 & 0.67 & $-0.26,1.59$ & 0.155 \\
\hline Fatigue & 2.96 & 4.09 & 1.13 & $0.21,2.05$ & $0.017^{*}$ \\
\hline Vigour & 10.74 & 10.22 & -0.52 & $-1.43,0.40$ & 0.270 \\
\hline TMD & -3.73 & -0.73 & 3.00 & $0.15,5.85$ & $0.039 *$ \\
\hline
\end{tabular}

*Statistically significant differences

$T M D$ (total mood disturbance $)=$ tension + depression + anger + fatigue - vigour. $C I$ confidence interval 
Table 3. Comparison of the scores on the profile of mood states (POMS) between subjects with and without previous use of mefloquine

\begin{tabular}{|c|c|c|c|c|c|}
\hline & \multicolumn{2}{|c|}{ Subjects with previous use $(n=70)$} & \multicolumn{2}{|c|}{ Subjects without previous use $(n=108)$} & \multirow{2}{*}{$\begin{array}{l}\text { Subjects with vs without } \\
\text { Previous use } P \text { value }\end{array}$} \\
\hline & Mean difference $(95 \% \mathrm{CI})$ & $P$ value & Mean difference $(95 \% \mathrm{CI})$ & $P$ value & \\
\hline \multicolumn{6}{|l|}{ Total } \\
\hline Tension & $0.17(-0.54,0.89)$ & 0.634 & $0.06(-0.45,0.56)$ & 0.828 & 0.787 \\
\hline Depression & $-0.06(-0.39,0.28)$ & 0.734 & $0.58(0.05,1.11)$ & $0.031^{*}$ & 0.075 \\
\hline Anger & $-0.77(-1.78,0.24)$ & 0.131 & $0.67(-0.04,1.37)$ & 0.063 & $0.028 *$ \\
\hline Fatigue & $0.41(-0.44,1.27)$ & 0.339 & $0.96(0.21,1.71)$ & $0.012 *$ & 0.349 \\
\hline Vigour & $0.77(-0.14,1.68)$ & 0.096 & $-0.54(-1.30,0.22)$ & 0.164 & $0.031 *$ \\
\hline TMD & $-1.01(-3.44,1.41)$ & 0.407 & $2.81(0.70,4.92)$ & $0.010^{*}$ & $0.021 *$ \\
\hline \multicolumn{6}{|l|}{ Males } \\
\hline Tension & $0.10(-0.93,1.13)$ & 0.846 & $0.07(-0.47,0.62)$ & 0.790 & 0.292 \\
\hline Depression & $0.05(-0.18,0.28)$ & 0.660 & $0.16(-0.19,0.52)$ & 0.355 & 0.619 \\
\hline Anger & $-1.12(-2.44,0.19)$ & 0.091 & $0.13(-0.72,0.97)$ & 0.764 & 0.960 \\
\hline Fatigue & $-0.03(-1.16,1.12)$ & 0.965 & $0.71(-0.15,1.57)$ & 0.104 & 0.182 \\
\hline Vigour & $1.00(-0.04,2.04)$ & 0.060 & $-0.02(-1.07,1.03)$ & 0.972 & 0.094 \\
\hline TMD & $-2.00(-4.93,0.93)$ & 0.175 & $1.09(-0.79,2.97)$ & 0.251 & 0.065 \\
\hline \multicolumn{6}{|l|}{ Females } \\
\hline Tension & $0.27(-0.75,1.28)$ & 0.595 & $0.04(-0.85,0.92)$ & 0.932 & 0.818 \\
\hline Depression & $-0.20(-0.94,0.54)$ & 0.586 & $1.02(-0.0003,2.04)$ & 0.050 & 0.099 \\
\hline Anger & $-0.30(-1.94,1.34)$ & 0.712 & $1.23(0.08,2.37)$ & $0.036^{*}$ & 0.742 \\
\hline Fatigue & $1.00(-0.37,2.37)$ & 0.146 & $1.23(-0.04,2.49)$ & 0.058 & 0.113 \\
\hline Vigour & $0.47(-1.21,2.15)$ & 0.574 & $-1.08(-2.19,0.04)$ & 0.058 & 0.120 \\
\hline TMD & $0.30(-3.95,4.55)$ & 0.886 & $4.58(0.74,8.43)$ & $0.021 *$ & 0.156 \\
\hline
\end{tabular}

* Statistically significant differences

$T M D($ total mood disturbance $)=$ tension + depression + anger + fatigue - vigour. $C I$ confidence interval

floquine before (Table 3). This difference was due to the significant increase on these domains among first-time users, whereas no changes were observed among previous users of mefloquine (Table 3). These changes were only statistically significant in female first-time users.

Comparison of the change in score on the POMS between subjects with and without reported adverse events showed that within subjects reporting neuropsychiatric adverse events the scores on the domains depression and fatigue, as well as the TMD (4.59 points, $95 \%$ CI 0.92 , 8.25 ) increased significantly (Table 4). Between the two groups significant differences were observed on the domains anger and vigour as well as the TMD.

\section{Discussion}

In this study, we found that mild neuropsychiatric adverse events during the first weeks of prophylactic use of mefloquine are common. This endorses the policy in some countries to start mefloquine prophylaxis at least 3 weeks prior to departure. If adverse events develop, they usually appear early at a time that the patient can still switch to another antimalarial. Mefloquine has acetylcholinesterase-inhibiting properties, and stereospecific inhibition of acetylcholinesterase has been reported [13, 14]. It is known that acetylcholinesterase inhibitors are able to affect the central nervous system resulting in anxiety, restlessness, disrupted concentration and memory, confusion, sleep disturbances and convulsions [15]. Hence, the adverse-reaction profile of mefloquine is compatible with its pharmacological activity. The high short-term risk of encountering neuropsychiatric events of approximately $32 \%$ among the population of young and healthy travellers who used mefloquine as malaria prophylaxis during the run-in period of 3 weeks is higher than the previously reported incidences of $11.2 \%$ [8], 17.4\% [11] and $18.7 \%$ [16]. It is possible that the fact that we explicitly
Table 4. Comparison of the scores on the profile of mood states (POMS) between subjects with and without neuropsychiatric adverse events (AEs)

\begin{tabular}{|c|c|c|c|c|c|}
\hline & \multicolumn{2}{|l|}{ Subjects with AEs $(n=58)$} & \multicolumn{2}{|c|}{ Subjects without AEs $(n=120)$} & \multirow[t]{2}{*}{$P$ value $^{\mathrm{a}}$} \\
\hline & Mean difference $(95 \% \mathrm{CI})$ & $P$ value & Mean difference $(95 \% \mathrm{CI})$ & $P$ value & \\
\hline Tension & $0.26(-0.64,1.16)$ & 0.567 & $0.03(-0.41,0.46)$ & 0.911 & 0.787 \\
\hline Depression & $0.97(0.16,1.77)$ & $0.019 *$ & $0.03(-0.31,0.36)$ & 0.883 & 0.075 \\
\hline Anger & $0.97(-0.33,2.26)$ & 0.142 & $-0.32(0.92,0.29)$ & 0.300 & $0.018^{*}$ \\
\hline Fatigue & $1.76(0.46,3.06)$ & $0.009^{*}$ & $0.26(-0.29,0.80)$ & 0.350 & 0.349 \\
\hline Vigour & $-0.64(-1.67,0.39)$ & 0.220 & $0.28(-0.44,0.99)$ & 0.449 & $0.031^{*}$ \\
\hline TMD & $4.59(0.92,8.25)$ & $0.015^{*}$ & $-0.28(-1.84,1.27)$ & 0.719 & $0.021^{*}$ \\
\hline
\end{tabular}

*Statistically significant differences

${ }^{\text {a }}$ Subjects with vs without AEs

CI confidence interval 
asked patients to report potential adverse effects may have caused a bias towards over-reporting. This bias could not be avoided as it is currently state of the art to treat people with a prophylactic dose of mefloquine for 3 weeks preceding travelling in order to be able to change treatment in case of neuropsychiatric adverse events [1]. In case of such events, people are advised to come back for alternative treatment. Nevertheless, the concurrent abnormalities on the POMS questionnaire confirm that these events are common and the differences between males and females and between first-time and regular users of mefloquine suggest a difference in vulnerability. A possible explanation for differences between males and females might be that females are more aware of neuropsychiatric disturbances than males and communicate this more easily than males. Another explanation for differences between males and females might be a gender-specific difference in bioavailability or metabolism of mefloquine, although such a difference was not demonstrated in one small study [17]. The fact that individuals with a history of mefloquine use did not demonstrate neuropsychiatric abnormalities on the POMS may be explained by the phenomenon of 'depletion of susceptibles'. This means that persons who encounter adverse events will not use the drug again whereas those without adverse events will use the drug again during their future travels.

Some authors have suggested that the physiological and psychological stress of intercontinental travel may be of importance for mefloquine-associated neuropsychiatric adverse events $[8,10,11]$. In this study, we tried to eliminate the effects of travel by assessing the adverse effects after the third tablet of mefloquine at the time that all subjects were still at home. Our results show that neuropsychiatric adverse events occur within 3 weeks after starting mefloquine and occur independently of intercontinental travel.

Before drawing conclusions we need to emphasise some limitations that may affect the internal and external validity of our study. Firstly, we compared changes within subjects who were all taking a prophylactic dose of mefloquine. Although this allowed for elimination of confounding by subject characteristics, all individuals were aware of the fact that they received active treatment. We could not include a placebo group for ethical considerations nor an actively treated comparator group since the alternative chemoprophylaxis is started on the day of departure. Therefore, we may have overestimated the effect on the POMS. Secondly, the external validity of our study may have been affected by the selection of our study population. The selection of the cohort is based on the prescription of mefloquine to persons planning to make a trip to a tropical area for which mefloquine is advised. The choice of chemoprophylaxis is based on the absence of contraindications for the drug and the tropical area visited. This leads to a selection of a relatively healthy cohort formed by first-time users (with no known contraindications for the drug) and travellers who had used mefloquine before but who did not encounter serious adverse events.
This shows that previous use of mefloquine should be taken into account when generalising the effects to the population of users of mefloquine for chemoprophylaxis.

In conclusion, mefloquine-associated neuropsychiatric adverse effects were demonstrated during the run-in period of 3 weeks of the use of a prophylactic dose of $250 \mathrm{mg}$ weekly. These effects were most common in women and first-time users. Future studies should further explore other risk factors for neuropsychiatric adverse events.

\section{References}

1. Landelijke Coordinatiecentum Reizigersadvisering (1999) Malariaprofylaxe bulletin

2. Bem JL, Kerr L, Stuerchler D (1992) Mefloquine prophylaxis: an overview of spontaneous reports of severe psychiatric reactions and convulsions. J Trop Med Hyg 95:167-179

3. Croft A, Garner P (1997) Mefloquine to prevent malaria: a systematic review of trials. BMJ 315:1412-1416

4. Sturchler D, Handschin J, Kaiser D, Kerr L, Mittelholzer ML, Reber R, et al (1990) Neuropsychiatric side effects of mefloquine. N Engl J Med 322:1752-1753

5. Weinke T, Trautmann M, Held T, Weber G, Eichenlaub D, Fleischer K, et al (1991) Neuropsychiatric side effects after the use of mefloquine. Am J Trop Med Hyg 45:86-91

6. Karbwang J, White NJ (1990) Clinical pharmacokinetics of mefloquine. Clin Pharmacokinet 19:264-279

7. van Riemsdijk MM, van der Klauw MM, van Heest JA, Reedeker FR, Ligthelm RJ, Herings RM, et al (1997) Neuropsychiatric effects of antimalarials. Eur J Clin Pharmacol 52:16

8. Schlagenhauf P, Steffen R, Lobel H, Johnson R, Letz R, Tschopp A, et al (1996) Mefloquine tolerability during chemoprophylaxis: focus on adverse event assessments, stereochemistry and compliance. Trop Med Int Health 1:485494

9. Barrett PJ, Emmins PD, Clarke PD, Bradley DJ (1996) Comparison of adverse events associated with use of mefloquine and combination of chloroquine and proguanil as antimalarial prophylaxis: postal and telephone survey of travellers. BMJ 313:525-528

10. Davis TM, Dembo LG, Kaye-Eddie SA, Hewitt BJ, Hislop RG, Batty KT (1996) Neurological, cardiovascular and metabolic effects of mefloquine in healthy volunteers: a double-blind, placebo-controlled trial. Br J Clin Pharmacol 42:415-421

11. Schlagenhauf P, Lobel H, Steffen R, Johnson R, Popp K, Tschopp A, et al (1997) Tolerance of mefloquine by SwissAir trainee pilots. Am J Trop Med Hyg 56:235-240

12. Wald FDM, Mellenbergh GJ (1990) De verkorte versie van de Nederlandse vertaling van de Profile of Mood States (POMS). Ned Tijdschr Psychol 45:86-90

13. Lim LY, Go ML (1985) The anticholinesterase activity of mefloquine. Clin Exp Pharmacol Physiol 12:527-531

14. Ngiam TL, Go ML (1987) Stereospecific inhibition of cholinesterases by mefloquine enantiomers. Chem Pharm Bull (Tokyo) 35:409-412

15. Hoover DB (1994) Cholinesterases and cholinesterase inhibitors. In: Craig CR, Stitzel RE (eds) Modern pharmacology, 4th edn. Little, Brown \& Co., Boston

16. Steffen R, Fuchs E, Schildknecht J, Naef U, Funk M, Schlagenhauf P, et al (1993) Mefloquine compared with other malaria chemoprophylactic regimens in tourists visiting east Africa. Lancet 341:1299-1303

17. Schwartz E, Potasman I, Rotenberg M, Almog S, Sadetzki S (2001) Serious adverse events of mefloquine in relation to blood level and gender. Am J Trop Med Hyg 65:189-192 